\title{
MEMORIA Y EXILIO: LA DIFÍCIL TAREA DE RECUPERAR VIDAS OLVIDADAS
}

\author{
Heloisa Paulo \\ Ceis20/Universidade DE CoImBRA
}

RESUMEN: La recuperación del individuo y el creciente interés por la memoria como un fenómeno histórico y social marcan los estudios biográficos dentro de la producción histórica contemporánea. En este campo, los trabajos realizados muestran los problemas del uso de la memoria individual, como fuente para los períodos más recientes de la historia, mientras que constantemente revelan contradicciones entre la versión oficial de una memoria histórica consolidada y el testimonio ofrecido por los que fueron alejados de esta memoria. En la historia reciente de los países ibéricos, donde los regímenes autoritarios llevaron al exilio forzoso a miles de personas, se ha producido una especie de amnesia forzada con respecto a la historia de la oposición a los regímenes dictatoriales. Fruto de la falta de fuentes o de una producción histórica comprometida políticamente, los espacios en blanco de un discurso supuestamente completado, una especie de semántica blanca de la producción histórica, serán decodificados a medida que se vayan encontrando los archivos y testigos del exilio. La recuperación de la trayectoria de los exiliados y emigrados políticos permite al historiador rellenar estas lagunas y reconstruir la historia de los movimientos de oposición, las condiciones de vida en el exilio, las relaciones entre los exiliados/emigrados políticos con las sociedades de acogida y los vínculos que existen, o no, con los emigrantes económicos. Tomando como punto de partida los exiliados portugueses, este trabajo pretende plantear algunas cuestiones teóricas y metodológicas relacionadas con la difícil tarea de la reconstrucción de las trayectorias vitales de los exiliados políticos y la posibilidad de replantearse su lugar en la memoria histórica de sus países.

PALABRAS CLAVE: Exilio, Biografía, Memoria, Portugal, Salazar, Opositores

\section{MEMORY AND EXILE: THE DIFFICULTT ASK OF RECOVERING FORGOTTEN LIVES}

\begin{abstract}
The recovery of the individual and the increasing interest in memory as a historical and social phenomenon mark biographical studies in contemporary historical production. Sometimes, the works about the recent periods of the history show the
\end{abstract}


contradictions between the official version of a consolidated historical memory and the people memory. In the recent history of the Iberian countries, the authoritarian regimes led to the forced exile of thousands of people. In these countries there has been a kind of forced amnesia regarding the history of the opposition to dictatorial regimes. As a result of missing documents or a politically engaged historical production are the whitespace of a discourse allegedly completed a sort of semantic white historical production. The recovery of the trajectory of exiles and political refugees enables the historian to fill these shortcomings and reconstruct the history of opposition movements. Based a Portuguese exiles history, this work aims at presenting some theoretical and methodological issues related to the difficult task the reconstruction of the life trajectories of political exiles and the possibility of to rethink her place in the historical memory of their countries.

KEY WORDS: Exile, Biography, Memory, Portugal, Salazar, opposition

\section{LA HISTORIOGRAFÍA CONTEMPORÁNEA Y LAS DICTADURAS IBÉRICAS DEL PASADO RECIENTE: LA BIOGRAFÍA DE LOS "OLVIDADOS"}

"De tal forma a História tem andado ao sabor dos regimes que acabámos amnésicos"1.

En abril de 2012, un grupo de historiadores españoles publicó una colección de artículos titulada En el combate por la historia ${ }^{2}$. La obra es una respuesta al Diccionario Biográfico de España, de 30 volúmenes, publicados por la Real Academia de la Historia, una colección en la que la historia reciente española se presenta desde la perspectiva de la propaganda franquista. Una vez más, aparece en España el problema de la interpretación de la historia reciente y su trascendencia política. Después de la condena de Baltasar Garzón y el gran debate sobre la Ley de la Memoria Histórica, la controversia viene a plantear temas importantes relacionados con el régimen "victorioso" de la Guerra Civil en el territorio español. La "voz de los vencidos" (el título de una de las publicaciones más respetadas en el exilio republicano) de nuevo vuelve a aparecer y se las arregla para movilizar partidarios ${ }^{3}$.

En este contexto, las biografías de los líderes republicanos emergen como una "respuesta" a la historiografía franquista, que han promocionado sus "héroes", como

${ }^{1}$ MÓNICA, Maria Filomena: "Biografia e Autobiografia", en M. de Sousa (coord.), Toda a Memória do Mundo, Lisboa, Esfera do Caos, 2007, p. 25.

2 VIÑAS, Ángel (ed.): En el Combate por la Historia. La Republica, La Guerra Civil, el Franquismo. Barcelona, Pasado y Presente, 2012.

3 ALTED VIGIL, Alicia: La voz de los vencidos. El exilio republicano de 1939. Madrid, Aguilar, 2005. 
Franco y Primo de Rivera ${ }^{4}$. Denigrados por la ideología del régimen, figuras como Francisco Largo Caballero, Juan Negrín o Manuel Azaña están perfilados por los historiadores de renombre que tratan de dilucidar su vida personal y política, y las marcas dejadas por el exilio y el olvido de sus nombres en la historia reciente de España ${ }^{5}$. La memoria histórica española tiene otra lectura, está "reconstruida" a través de estos y otros "fantasmas" rescatados de la oscuridad a la que fueron relegados por Franco y su interpretación de la Guerra Civil ${ }^{6}$.

La necesidad de redescubrir una memoria "borrada" está presente en España y en otros países donde la historia reciente es marcada por regímenes dictatoriales. Es el caso de algunos países latino-americanos, como Argentina o Brasil. Actualmente, investigadores de ambos países buscan superar la memoria traumática de las dictaduras militares y trabajar con los problemas del exilio reciente ${ }^{7}$.

En Portugal, si bien la Revolución del 25 de abril 1974 ha tratado de recuperar la memoria de la oposición, "olvidada" por el régimen anterior, todavía queda mucho por recuperar. La historiografía sobre el movimiento de oposición está marcada por las obras clásicas, a pesar de la atención que ha recibido por parte de los historiadores en los últimos años ${ }^{8}$. El peligro del revisionismo está presente en la "historia" escrita por "historiadores aficionados", que encuentran en los medios de comunicación sensacionalistas audiencia sobre sus reinterpretaciones del pasado. Por ejemplo, los polémicos trabajos de Rui Ramos acerca del carácter no dictatorial del régimen salazarista suscitan reacciones de los

\footnotetext{
${ }_{4}$ Acerca de una mirada franquista, véase Pio Moa, en especial, Franco. Un balance histórico. Madrid, Planeta, 2006. Acerca de Primo de Rivera, véase, IMATZ, Arnaud: José Antonio: Entre odio y amor. Su historia como fue. Madrid, Editorial Altera. 2006.

5 Véase como ejemplo ARÓSTEGUI, Julio: Largo Caballero. El tesón y la quimera. Barcelona, Debate, 2013; FUENTES, Juan Francisco: Francisco Largo Caballero, el Lenin español. Madrid, Editorial Síntesis, 2005; JULIÁ, Santos: Vida y tiempo de Manuel Aqaña. Madrid, Taurus, 2008; MORADIELLOS, Enrique: Don Juan Negrín. Madrid, Editorial Quinteto, 2008; JACKSON, Gabriel: Juan Negrín, médico, socialista y jefe del gobierno de la II República Española. Barcelona, Crítica, 2012.

${ }^{6}$ Véanse ARÓSTEGUI, Julio y GODICHEAU, François (eds.): Guerra Civil. Mito y Memoria. Madrid, Marcial Pons, 2006; AGUILAR FERNANDEZ, Paloma: Memoria y Olvido de la Guerra Civil Española. Madrid, Alianza, 1996; y publicaciones periódicas, por ejemplo Espagne. La mémoire retrouvée 1975-2002. Matériaux pour l'bistoire de notre temps, n. 70 (2003).

7 Véanse como ejemplo JENSEN, Silvina: La provincia flotante. Historia de los exiliados argentinos de la última dictadura militar en Cataluña (1976-2006). Barcelona, Fundació Casa Amèrica Catalunya, 2007; FRANCO, Marina: El exilio. Argentinos en Francia durante la Dictadura. Buenos Aires, Ed. Siglo XXI, 2008; ROLLEMBERG, Denise: Exílio. Entre raízes e radares. Rio de Janeiro, Record, 1999.

${ }^{8}$ Los estudios acerca del movimiento contra la dictadura y el salazarismo tienen algunos trabajos clásicos: MARQUES, A.H. de Oliveira: A unidade da Oposição à Ditadura (1928-1931), Lisboa, Europa-América, 1973; REIS, Célia: A Revolta da Madeira e Açres (1931). Lisboa, Livros Horizonte, 1990; FARINHA, Luís: O reviralho: revoltas republicanas contra a ditadura e o Estado Novo: 1926-1940. Lisboa, Estampa, 1998; RABY, Dawn Linda: $A$ Resistência Antifascista em Portugal. 1941-1974. Lisboa, Salamandra, 1988; MARTINS, Susana: Socialistas na Oposição ao Estado Novo. Lisboa, Casa das Letras, 2005 y MADEIRA, João: Os engenheiros de Almas. O Partido Comunista e os Intelectuais. Lisboa, Editorial Estampa, 1996.
} 
historiadores contrarios a este "revisionismo histórico" ". En el caso español, entre otras muchas referencias, podría mencionarse las polémicas obras de Pío Moa sobre la Guerra Civil y el franquismo.

En ambos países, sin embargo, la memoria de la oposición y la represión se ha "construido" desde los años inmediatamente posteriores al fin de las dictaduras, lo que no significa que se haya hecho de forma "integral". Las peculiaridades del caso español llevaron al estudio de la realidad del exilio antes que en Portugal. En los núcleos de exiliados, en particular en México, incluso antes de la instauración de la democracia en España, los primeros trabajos sobre el exilio republicano contemplan memorias y escritos políticos, los frutos de los esfuerzos para mantener vivo el ideal de la República y la memoria de la Guerra Civil. Estas publicaciones sirven como base para el desarrollo de toda la historiografía centrada en este tema, que tiene como objetivo dar una nueva visión del exilio y del golpe de $1936^{10}$.

En el caso de Portugal, la memoria de la resistencia al salazarismo está dominada por los partidos triunfantes después de la Revolución de los Claveles o 25 de abril, en 1974. Cada grupo que surge organizado políticamente defiende para sí mismo el papel principal en la lucha clandestina haciendo uso de historias y recuerdos de la lucha durante la dictadura. La memoria de la oposición queda apoderada por una lista de las memorias individuales y partidarias, traducidas en obras de inclinación partidista. Los actuales victoriosos buscan resaltar su papel como oposición, en muchos casos para justificar su busca de un papel destacado en el nuevo orden político. Por lo tanto, se construye una especie de "memoria oficial", vinculada a los partidos y los contextos ideológicos de aquellos que hacen público su testimonio. Comunistas y socialistas tienen diferentes versiones de la historia de la oposición. En cada uno de ellos, el papel de los miembros del partido se promociona como fundamental en la lucha contra el régimen ${ }^{11}$.

\footnotetext{
${ }_{9}^{9}$ Véanse RAMOS, R., SOUSA, B. y MONTEIRO, G.: História de Portugal. Lisboa, Esfera dos Livros, 2012. ${ }^{10}$ Véase ABELLÁN, José Luis (coord.): El Exilio Español de 1939. Madrid: Taurus, 1976, 6 v.; DREYFUSARMAND, Geneviève: El exilio de los republicanos españoles en Francia. Barcelona, Crítica. 2000; SCHWARZSTEIN, D.: Entre Franco e Perón. Memoria e identidad del exilio republicano español en Argentina. Barcelona, Crítica. 2001; ALTED, Alicia: op. cit:; SAMPER, M. R.: La oposición durante el franquismo. El exilio republicano. Madrid, Encuentro, 2005; TOBAR, Ernesto Mächler (coord.): L'exil Espagnol dans les Amériques. Paris, Indigo, 2011. Para el combate contra el franquismo en España, véase ORTIZ, Jean (dir.): Rouges: Maquis de France et d'Espagne. Les Guerilleros. Biarritz, Atlantica, 2006; MORENO GÓMEZ, Francisco: La resistencia armada contra Franco. Tragedia del maquis y la guerrilla. El Centro-Sur de España: De Madrid al Guadalquivir. Barcelona, Crítica, 2001.

11 Véanse, entre otros, PAULO, Heloisa: "Uma memória dos opositores sobre o regime e sobre a Oposição", en L. R. Torgal y H. Paulo (coords.): Estados Autoritários e Totalitários e suas Representações. Coimbra, Imprensa da Universidade, 2009, pp. 376-388.
} 
Sin embargo, este intento de construir "memorias propias" pone de relieve las contradicciones existentes en las diferentes interpretaciones de los hechos. Mucho más que revelar la necesidad de asegurar el papel principal en la historia de la oposición política, la dificultad de consenso demuestra las profundas divisiones del movimiento opositor. No se trata solamente de la existencia de visiones diferenciadas acerca de los hechos, sino también de omisiones deliberadas de personas y eventos. Por ejemplo, en sus testimonios históricos, los comunistas que participaron en las primeras revueltas contra la dictadura militar no revelan hechos importantes. Fruto de memorias selectivas o de orientaciones partidarias, las omisiones buscan disminuir la importancia de las revueltas capitaneadas por los republicanos del "Reviralho"12.

En lo que respecta a los estudios sobre la oposición en el exilio, a diferencia de lo que ocurre en la historia española, sigue siendo un campo inexplorado ${ }^{13}$. Muchos de los exiliados y sus trayectorias en el extranjero están completamente olvidados o son poco conocidos. Por ello, la propia historia de la oposición a la dictadura y al salazarismo tiene mucho de desconocido e inexplorado. Los movimientos de los opositores en el exilio o las versiones de los exiliados acerca de su papel en la resistencia antes de su partida son todo un campo de investigación nuevo.

Las biografías, en especial, son casi inexistentes. Con excepción de algunas obras panegíricas, que no pueden ser consideradas de carácter científico ${ }^{14}$, y las descripciones taxonómicas que figuran en el Diccionario do Estado Novo o en el Diccionario da República ${ }^{15}$, no tenemos muchos más trabajos realizados. Las biografías, además, son menos numerosas que las autobiografías, aunque la historia biográfica está de "moda". En esta área, hay que distinguir dos períodos en los cuales este tipo de problema es más frecuente:

Un primer período abarcaría los años de las revueltas llamadas de "Reviralho" (1927-1931) y se termina en la década de los cuarenta. Se caracteriza por dos grandes conflictos que incluyen la participación de los exilados portugueses: la Guerra Civil y la Segunda Guerra Mundial. Para estos años hay una dificultad de acceso a los archivos

\footnotetext{
${ }^{12}$ Reviralho es la designación para las primeras revueltas contra la dictadura militar (1926-1940). Véanse PAULO, Heloisa (org.) Memórias das Oposições (1927-1969). Coimbra, Minerva Editora, 2010.

${ }^{13}$ Acerca del exilio véanse, entre otras publicaciones: MARQUES, A. H. Oliveira: A Liga de Paris e a ditadura militar (1927/1928), Lisboa, Europa-América, 1976; CLÍMACO, Ana Cristina: L’Exil politique portugais en France et en Espagne, 1927-1940. Tesis doctoral presentada en la Universidad de Paris 7 (Denis Diderot) en 1998; SILVA, Douglas Mansur: A Oposição ao Estado Novo no Exílio Brasileiro 1956-1974. Lisboa, Imprensa de Ciências Sociais, 2006.

${ }^{14}$ Véanse ROSA, Frederico: D. Humberto Delgado. Biografia do General Sem Medo. Lisboa, A Esfera do Livro, 2008.

${ }^{15}$ ROSAS, F. y BRITO, Brandão: Dicionário do Estado Novo. Lisboa, Estampa, 1996 (2 volumes). El Dicionário da República, coordinado por Fernanda Rolo, previsto para salir en 2010, se encuentra en proceso de publicación.
} 
personales de los opositores y son escasas las memorias de los exilados, a pesar de la publicación de algunas autobiografías, escritas en su mayoría por comunistas y algunos anarquistas $^{16}$. La participación en las luchas de diferentes países y la movilidad a la que están obligados tienen como consecuencia la desaparición de los archivos personales y de instituciones formadas por los exilados en los países de acogida. La documentación, si la hubiera, está en los países de acogida, áreas geográficamente diversas, como España, Francia, Bélgica, Marruecos, Argelia y Brasil. El problema abarca también a los periódicos publicados en el exilio, la mayoría no conservados en bibliotecas públicas.

Otro período abarcaría una etapa de gradual "debilitamiento" del régimen y el aumento del movimiento de oposición, de los años cincuenta hasta 1974. Tenemos más memorias y un mayor acceso a los archivos personales, sobre todo porque gran parte de los exilados retornaron después de la caída del régimen de Salazar. Junto con los opositores tradicionales del régimen forzados al exilio, hay un nuevo tipo de exiliado: los desertores de la guerra colonial, entre los cuales tenemos un gran grupo de nuevos opositores. El contexto geográfico es también diferenciado, incluso con nuevos locales de acogida como los países salidos de la descolonización, como Argelia y Marruecos. El acceso a la documentación es más facilitada gracias a los centros documentales de historia contemporánea creados en los últimos años, como lo Centro de Documentación 25 de Abril de la Universidad de Coímbra. Por otro lado, con el surgimiento de regímenes dictatoriales en países de acogida, como ocurrió en América Latina, muchos exiliados han destruido la documentación "de izquierdas" que podría poner en peligro su permanencia en estos países. Esta situación también ha llevado a algunos exiliados a combatir junto con los guerrilleros que luchaban contra estas dictaduras. Esta especie de transición de la condición de exiliado a guerrillero ha comprometido una vez más los archivos personales. Algunos de los que combatieron en ambos lados pasaron a la condición de apátridas con dificultades de tener residencia en los países por los cuales combatieron ${ }^{17}$. A pesar de los acontecimientos, el período que comienza en los años cincuenta ofrece un mayor número de documentos. Sin embargo, han desaparecido muchos archivos, algunos de ellos provenientes de instituciones fundadas por los exiliados en exterior, como ha ocurrido con la documentación de Gremio Republicano Portugués de la ciudad de São Paulo, Brasil.

\footnotetext{
16 Véase CATARINO, Horta: Falando do Reviralho. Lisboa, Ed. Do Autor, 1977; JORGE, Joaquim Pais: Com uma alegria imensa. Notas autobiográficas. Lisboa, Avante, 1984.

${ }^{17}$ Un ejemplo es Alípio de Freitas, un cura portugués que viajó a el Brasil en los años cincuenta. Después de 1964, con la dictadura militar, Alípio pasa a colaborar con los guerrilleros. Por ello, fue encarcelado en Brasil y pierde la ciudadanía portuguesa. En 1981, con la redemocratización brasileña vuelve a Portugal. Véase, entre otros, CARDOSO, L. Costa: "Construindo a memoria do regime de 64" (www.anpuh.org/arquivo/download?ID_ARQUIVO=3750, consultado en 10 de mayo de 2013).
} 
Sin embargo, la ubicación de los archivos perdidos por sí misma no resuelve el problema de la reconstrucción de las trayectorias de la oposición en el exilio. La necesidad de adaptar los diferentes grupos de exiliados a los países receptores, así como sus condiciones políticas y económicas, demarcan los límites de sus actividades en el extranjero. El conocimiento de la historia nacional de cada lugar de exilio se convierte en una herramienta fundamental para el historiador que se centra en los exiliados y su combate contra el régimen en exterior. Además, la conservación de los archivos personales por los descendientes de los opositores no es una práctica muy común, especialmente en América Latina. El distanciamiento de las generaciones más jóvenes de sus orígenes lleva al olvido del pasado familiar y, en consecuencia, a la devaluación de la documentación de una historia y un país que no se conoce ${ }^{18}$. Esta sucesión de obstáculos hace que muchos de los que participaron en el movimiento de oposición durante estos años y se vieron obligados a exiliarse "desaparecían" de la memoria, dominada por la versión presente en archivos del régimen y en la historia oficial del Partido Comunista. Así, perdida la memoria del exilio, también se pierden versiones únicas de los acontecimientos anteriores a la gran peregrinación des los exiliados. Aspectos de la lucha en los países de origen se quedan olvidados por la desaparición de los archivos en el extranjero.

\title{
2. EL EXILIO Y LA PRESERVACIÓN DE LAS MEMORIAS: TRABAJAR CON FRAGMENTOS
}

\begin{abstract}
"Já tarde, a caravana pôs-se em marcha; mulheres e crianças por pequenos grupos, acompanhadas de alguns homens à frente atrás a pequena carreta de bois, com a sua desmesurada pirâmide, acompanhada por outro grupo de homens. A vereda por onde baixávamos era não só em pendente rapidíssima, mas sobre a borda duma ravina abrupta, uma e outra totalmente recobertas por espessa neve. Eu seguira à frente com minha mulher, carregando uma pequena mala de manuscritos, que quase nunca abandonava. Súbito ouviu-se atrás um carro com toda a carga pela ravina abaixo. Em cima restavam os bois e junto deles o grupo do carreiro e dos acompanhantes, gesticulando com desespero. Nos primeiros momentos assaltou-me uma aflição horrível. No fundo da imensa ravina, enterrados na neve, iam ficar os meus escassos bens, alguns salvos já de tantos naufrágios. $" 19$
\end{abstract}

${ }^{18}$ El Gremio Republicano Portugués do Rio de Janeiro, fundado en 1908, originalmente tiene su archivo en manos de los descendientes de José Augusto Prestes, su ultimo director. No obstante, su hija ha declarado que todos los documentos se han tirado a la basura. Testimonio de Maria Luísa Prestes, abril de 2004.

${ }^{19}$ CORTESÃO, J: "No desfecho da Guerra de Espanha", en 13 Cartas do Cativeiro e do Exílio (1940). Lisboa, Biblioteca Nacional, 1987, p. 150. 
Una de las dificultades en la reconstrucción de las trayectorias de los exiliados es la falta de documentación. El exilio significa el desplazamiento forzado y, en la mayoría de los casos, el abandono de todos los bienes acumulados en el curso de una vida. Los exiliados llevan consigo sólo fragmentos del pasado, perdiendo, a veces, su identidad como ciudadanos, ya que se les niega la ciudadanía, tanto en el espacio de origen como de acogida. Este tipo de "renuncia forzada" a una vida que se deja atrás con el exilio, a menudo implica la destrucción de documentos y objetos que podrían proporcionar pistas fundamentales para que el historiador pueda reconstruir la trayectoria de los exiliados.

La Guerra Civil española está repleta de ejemplos de "eliminación" de las pruebas $^{20}$, tales como la destrucción de gran parte de la documentación del Ministerio de Propaganda, en el primer ataque realizado contra el Madrid por las tropas franquistas ${ }^{21}$. Sin embargo, tenemos intentos desesperados de "guardar la memoria", como el traslado a territorio francés por parte del Jefe de Estado Mayor Manuel Estrada Manchón de la documentación de la Sección de Información del propio Estado Mayor ${ }^{22}$.

Pero no es necesaria una guerra civil para destruir importantes documentos. Para aquellos que viven en la clandestinidad, la necesidad de escapar de las olas de la represión a menudo fuerza a la destrucción de documentos que podrían comprometer a otros. La destrucción ocasional o intencional de documentos de las fugas es un elemento común, porque pueden poner en peligro la supervivencia de sus propietarios, familiares o amigos. Fruto de la persecución o de la clandestinidad, esta pérdida de la documentación se ve agravada por las condiciones del exilio. El constante cambio de domicilio e incluso país, obliga al exiliado a realizar una selección de lo que más se necesita llevar. En la mayoría de los casos de los exiliados, el historiador está obligado a utilizar la versión "oficial" de los hechos, producida por el aparato de represión, distorsionada por el discurso de la burocracia y la necesidad de "mostrar el trabajo"23.

\footnotetext{
${ }^{20}$ Véanse, entre otros, BOZA PUERTA, Mariano y SÁNCHEZ HERRADOR, Miguel Ángel: "El Martirio de los libros: una aproximación a la destrucción bibliográfica durante la Guerra Civil", Boletín de la Asociación Andaluza de Bibliotecarios, 86- 87 (Enero-Junio 2007), pp.79-95.

${ }^{21}$ Rubio Hidalgo, responsable de la Oficina de Prensa Extranjera y Propaganda del Ministerio de Propaganda había destruido los archivos. Ver: PRESTON, Paul: Idealistas bajo las balas. Corresponsales extranjeros en la Guerra de España. Barcelona, Debolsillo, 2008, p. 39. Acerca de la prensa y propaganda véanse, entre otros, PENA RODRÍGUEZ, Alberto: "La Propaganda de la Historia. La relación entre la Historia y la Comunicación en el entorno ibérico contemporáneo", Estudos do Século XX, 11 (2011), pp. 15-28.

$22 \mathrm{El}$ archivo fue entregado a Leandro Garcia, un refugiado en Burdeos que lo conservó hasta su muerte. En 1988, el Estado Español negocia su traslado a España. Véase http://pares.mcu.es/ParesBusquedas/servlets/Control_servlet?accion=2\&txt_id_fondo=117016, consultado a 12 de diciembre de 2012).

${ }^{23}$ Véase PAULO, Heloisa: "A imagem oficial. Os Budas e a Espionagem Salazarista”, en M. L. T. Carneiro y F. Croci (orgs): Tempos de Fascismos. Ideologia - Intolerância - Imaginário. São Paulo, EDUSP/APSP/Imprensa Oficial, 2010, pp. 181-195.
} 
La desaparición de los documentos, olvidados en la huída, destruidos por la necesidad de mantener las actividades en sigilo o perdidos en las rutas del exilio, no puede significar la desaparición de memorias y personas que han luchado años por su supervivencia y por la llegada de la democracia en sus países. Las marcas del paso de los opositores antifascistas exiliados se quedan en los caminos del exilio. Las actividades económicas, las relaciones establecidas con la sociedad local, las publicaciones y las manifestaciones públicas se encuentran registradas en la prensa local y en los archivos oficiales de los países de acogida. Las autorizaciones de entrada, estancia, residencia o permanencia están en los archivos oficiales, así como las actividades políticas desarrolladas por los exiliados, muchas controladas por las autoridades locales. En Brasil, los informes do Departamento de Orden Política y Social de São Paulo, responsable por el control policial, proporcionan informaciones sobre los opositores portugueses y españoles sobre sus actividades profesionales y políticas, incluso acerca de sus vidas particulares.

Sin embargo, también hay que tener en cuenta la documentación consular y los informes acerca de la acciones de los exiliados, enviados para los países de origen. En el caso portugués, los archivos del Ministerio de Asuntos Exteriores, los fondos de la Policía Política y del archivo Salazar pueden proporcionar informaciones para la investigación, a pesar del compromiso de las fuentes oficiales descrito anteriormente ${ }^{24}$.

La exploración de este universo de las fuentes es necesario si queremos romper las versiones oficiales de los partidos o regímenes sobre el movimiento de oposición. Sin invalidar las versiones existentes, es preciso rescatar nuevos documentos con el objetivo de cambiar interpretaciones limitadas por la escasez de datos. De este modo, en la historia de Portugal, incluso Ibérica, se podría iniciar un proceso (o no) de revisión o revalidación de la historiografía existente y se podría comprender mejor el papel desempeñado por los personajes hasta ahora olvidados.

\section{LA (RE)CONSTRUCCIÓN DE LA MEMORIA DEL EXILIO: ENTRE LA HISTORIA Y LOS MITOS}

"Partilho da convicção de que só o cruzamento sistemático de diferentes testemunhos nos pode aproximar da melhor compreensão global das particularidades de cada caso. A História contemporânea de Portugal e dos portugueses vai-se fazendo...também com os contributos daqueles que, com ou sem razão, julgam ter dela feito parte.

\footnotetext{
${ }^{24}$ Acerca de los problemas de los archivos véanse COEURÉ, Sophie: Archives interdites. L’histoire confisquée. Paris, La Découverte, 2001.
} 
Que essa História não venha, mais uma vez, a ser apenas configurada obedecendo ao critério da relativa "altura" mistificada das individualidades mencionadas... ou por desejos de promoção pessoal ou de auto elogio familiar; e não pela excepcionalidade e exemplaridade da entrega de tempos de vida e vidas, a causas comuns... é um dos motivos do relato destas "andanças", de "baixíssimas" mas exemplares individualidades de que mais ninguém provavelmente falará.

Por último, desejo sublinhar que, como qualquer outro, estou consciente de padecer, e ainda bem, das subjectividades inerentes à condição humana, susceptíveis de influenciar, num ou noutro sentido as apreciações e descrições destas "andanças" 25

Los estudios biográficos cogieron un nuevo impulso en los últimos años con la recuperación del género realizada por los historiadores de la "Nueva Escuela" francesa ${ }^{26}$. En verdad, la tradición de los Annales había introducido una visión diferenciada de las antiguas narrativas heroicas con el clásico trabajo de Lucien Febvre ${ }^{27}$. Desde la década de los ochenta, políticos, religiosos e incluso personas sin renombre en la historia han sido analizados en trabajos que pretenden romper con los modelos biográficos producidos en los siglos pasados. Combinando datos personales con el estudio del período, la vida de las grandes figuras no constituye un hecho único, sino uno de los aspectos de la realidad de su tiempo. El acto individual es considerado como el reflejo de una época, las memorias y visiones de los actores acerca de su proprio papel, pero los problemas son más complejos cuando hablamos del exilio y de la contemporaneidad ${ }^{28}$.

Las biografías de los exiliados por el régimen de Salazar están iniciándose. Pero la mayoría de los estudios tienen un problema común: el mito del héroe. Trabajar con nombres como Humberto Delgado y Álvaro Cunhal es una tarea que presupone la confrontación con imágenes construidas por el propio movimiento opositor. Sus imágenes eran y son utilizadas como banderas de la resistencia al fascismo portugués ${ }^{29}$. Las

\footnotetext{
${ }^{25}$ MORTÁGUA, Camilo: Andanças para a Liberdade. Lisboa, Esfera do Caos, 2009, p. 213. Camilo Mortágua participó en el movimiento opositor en el exilio durante las décadas de los 60 y 70. Colaboró con los opositores españoles en el Directorio Revolucionario Ibérico de Liberación y participó en el secuestro del paquebote Santa Maria en 1961. Véase PAULO, Heloisa: "1961: o Assalto do Santa Maria e o desmoronar do regime salazarista em Portugal", História Revista 16 (2011), pp. 53-80.

26 Algunos de los trabajos publicados a partir de los años 80 reflejan esta recuperación del género biográfico. Véase, entre otros, LE GOFF, Jacques: Saint Louis. Paris, Gallimard, 1996 e FERRO, Marc: Petain. Paris, Fayard, 1987.

${ }^{27}$ FEBVRE, L.: Martim Lutero, um destino. Lisboa, Livraria Bertrand, 1976.

${ }^{28}$ Las dificultades de trabajar la cuestión es apuntada por los clásicos como BOURDIEU, Pierre: "A ilusão biográfica", en Razõos práticas: sobre a teoria da acção. Oeiras, Celta, 1997; LE GOFF, Jacques: "Comment écrire une biographie historique aujourd'hui", Le Débat, 54, (1989); CHARTIER, Roger: "Figures rhétoriques et représentations historiques", en $A u$ bord de la falaise. L'bistoire entre certitudes et inquiétude. Paris, Albin Michel, 1998. Véanse otros trabajos como el de PIKETTY, Guillaume: "La biographie comme genre historique? Étude de cas", Vingtième Siècle. Revue d'histoire. nº 63 (juillet-septembre 1999), pp. 119-126.

${ }^{29}$ Acerca de Álvaro Cunhal, entre las obras más completas véanse PEREIRA, José Pacheco: Álvaro Cunhal: Uma Biografia Política. Vol I: «Daniel» o Jovem Revolucionário (1913-1941). Lisboa, Temas e Debates: 1999; Vol. II: «Duarte», O Dirigente Clandestino (1941-1949), 2001; Vol. III: O Prisioneiro (1949-1960), 2005.
} 
"versiones oficiales" del los mitos son repetidas en inúmeras obras y, por veces, es difícil superar el mito y trabajar con otra imagen.

Un caso paradigmático es el relato biográfico del candidato opositor en las elecciones de 1958, el General Humberto Delgado. La obra más reciente, escrita por un su nieto, Frederico Delgado Rosa, es una versión construida para a glorificación del antiguo colaborador de Salazar como héroe de la Oposición. La trayectoria del biografiado se construye a partir de una selección de documentos del archivo personal de Delgado. La utilización de sus escritos y sus publicaciones proporcionan al lector una visión de la realidad del exilio y de la oposición a partir de la óptica del personaje estudiado. Así, la propia descripción del régimen de Salazar está condicionada por la trayectoria de Delgado. El período en que Humberto Delgado fue su colaborador, el régimen es descrito con colores suaves. Después de su ruptura con Salazar, el gobierno es caracterizado como una $\operatorname{dictadura}^{30}$. El resultado es una interpretación confusa de la realidad histórica y del papel político jugado por Delgado, desde su vinculación a la dictadura hasta la oposición. De igual forma, su periplo como exiliado es narrado prescindiendo de todo el universo de documentos producidos por los demás opositores acerca del General y sus vivencias en el exilio. Sin embargo, los relatos de otros exiliados contradicen la imagen de "gran jefe" de la oposición defendida por el propio Delgado y reproducida por su nieto en la citada biografía, que puede considerarse más bien una "hagiografía" 31.

Con todo, si hay "héroes" consagrados, también hay personajes anónimos y "olvidados" por la historiografía contemporánea. Los opositores que formaron parte del llamado "Reviralho" en Portugal siguen siendo ignorados por muchos historiadores actuales. Un ejemplo es el grupo de políticos portugueses exiliados en Madrid durante la II República española. Las actividades de oposición a la Dictadura Portuguesa de figuras de gran relevancia política, como Jaime de Morais, antiguo gobernador de las Indias Portuguesas, el historiador y ex director de la Biblioteca Nacional Jaime Cortesão o el antiguo Ministro de la Justica, Alberto Moura Pinto, son poco conocidas. Muy recientemente comenzaron a ser estudiados los vínculos entre los exiliados portugueses y los republicanos españoles, en especial con los líderes y los partidos socialistas y anarquistas. La correspondencia epistolar entre los tres opositores y diversos miembros del gobierno republicano revelan una intensa colaboración política, que quedó patente en el

\footnotetext{
30 Para una visión de los estudios acerca de la memoria opositora en Portugal, véase VENTURA, António: Memórias da Resistência. Lisboa, Biblioteca Museu da República e da Resistência-Camara Municipal de Lisboa, 2001

31 Véanse, entre otros, el testimonio de CARVALHAL, Luís Abreu de Almeida: A verdade sobre Humberto Delgado no Brasil. Cartas inéditas, notas e comentários, Rio de Janeiro, Editora Brasil-América, 1986.
} 
episodio de la Revuelta de Asturias. Pero también durante la Guerra Civil y el exilio unos y otros mantuvieron un estrecho vínculo político y personal ${ }^{32}$.

No se trata de un problema relacionado con el olvido o la asignación de la categoría de "héroe" a quien pueda merecerlo, sino, sobre todo, con la elaboración honesta y profesional de los relatos biográficos. Para construir biografías, hay que tener en cuenta la diferenciación entre la imagen y la trayectoria de los hombres ${ }^{33}$. La imagen es una elaboración y, como tal, solamente puede mirar en una dirección, en especial, en el caso de los héroes de un movimiento. Pero, incluso los líderes son fruto de todo el pasado individual y de las decisiones tomadas durante la vida. La realidad histórica puede no corresponder al mensaje ideológico traspasada por el discurso biográfico elaborado por la oposición. Así como el descubrimiento de los archivos del exilio puede revelar conductas que no se adaptan al contenido de la descripción mítica de los héroes. Los problemas son diversos y complexos, porque están relacionados a toda una simbología de años de combate contra dictaduras.

Determinados trabajos acerca de la resistencia al nazismo y el fascismo ofrecen fórmulas interesantes para la resolución de algunos de estos problemas. Los estudios acerca de los principales nombres de la Resistencia Francesa revelan la importancia de una investigación que trabaje las trayectorias personales a partir de las condiciones históricas. Ninguna persona puede huir de la historia. Las decisiones tomadas en el pasado o el presente son fruto del compromiso del individuo con su tiempo. Los análisis de las trayectorias individuales deben tener en cuenta las restricciones y las respuestas dadas por los individuos ante los problemas impuestos por la historia local o nacional ${ }^{34}$. La fórmula es quizá antigua, pero eficaz. Los maniqueísmos presentes en las versiones biográficas oficiales no pueden ser perpetuados por la investigación histórica. Por ejemplo, los estudios sobre el compromiso gradual de los franceses en la resistencia, ayudan a desmitificar la idea de espontaneidad e inmediata adhesión de todos los franceses a la lucha contra la ocupación, incluso de los miembros más importantes del movimiento ${ }^{35}$.

\footnotetext{
32 Véanse PAULO, Heloisa (org.): Memórias... op. cit.

${ }^{33} \mathrm{El}$ problema de la construcción de la imagen del líder ha sido tratado en diversas obras. Véanse, entre otras, BURKE, Peter: A Fabricação do Rei: A Construção da Imagem pública de Luís XIV. Rio de Janeiro, Jorge Zahar, 1994. Más específicamente con relación a líderes de la resistencia, véase, entre otros, el trabajo de FRATISSE, Michel: Jean Moulin ou la fabrique d'un Héros. Paris, L'Harmattan, 2011.

${ }_{34}$ Para una visión sobre la relación del individuo y el proceso histórico, véase, entre otros, FERRO, Marc: Les individus face aux crises du XXe siècle: L'Histoire Anonyme. Paris, Odile Jacob, 2005.

35 Véase, entre otros, el estudio biográfico de Jean Moulin por AZEMA, Jean Pierre: Jean Moulin le rebelle, le politique, le résistant. Paris, Perrin, 2006, o el trabajo de VAST, Cécile: L'identité de la Résistance. Paris, Payot, 2010.
} 
Los peligros de las reconstrucciones biográficas de los "olvidados" son diversos cuando la recuperación comporta un cierto sentimiento de "búsqueda de justicia". El rescate de la memoria no puede dejar que el discurso mítico se sobreponga a la investigación historiográfica ${ }^{36}$. Esta presuposición básica para el historiador debe fortalecerse más en los casos de las biografías de los personajes de la oposición, ya que los diversos movimientos de oposición tienden a crear sus propios "héroes". La reconstrucción de trayectorias de vida aparece como una especie de "campo minado", en el cual el historiador frecuentemente es "obligado" a refutar algunos de los atributos de personajes heroicos. No obstante, la tarea principal del historiador como investigador es luchar contra los "tabús", sin dejar espacio para los datos que se presentan y que pueden ser rechazados por creencias políticas. Si este tipo de tarea es relativamente fácil cuando se trata de figuras como Luis XIV, Franco o Salazar, el proceso es mucho más complicado en el caso de las figuras de la oposición, víctimas del "olvido" impuesto en el pasado. Cualquier "cuestionamiento" sobre la conducta de los "héroes" presente en el discurso mistificado, puede ser visto como un intento de "blanquear" el régimen anterior y querer poner en descrédito la lucha de la oposición ${ }^{37}$.

En este contexto, el trabajo con las biografías de los exiliados es mucho más complejo. Comprender sus trayectorias es traspasar el "olvido", pero también el mito del discurso opositor que determinados movimientos de exiliados han construido ${ }^{38}$. Por otro lado, sus estrategias políticas son más difíciles de comprender que las de los biografiados que quedaron fijados en el mismo "espacio nacional". En la intersección de diferentes momentos que componen la totalidad de una vida en el exilio se superponen historias nacionales y locales. En esta complejidad de los datos cruzados, algunos de los vínculos que se establecen en el tiempo del exilio no son fáciles de entender, lo que requiere una mayor exploración de otras biografías y archivos para aclarar las razones políticas de determinadas opciones de lucha. El análisis de las apuestas políticas, vínculos y alianzas sobre temas comunes, o incluso los lazos sociales y familiares son pistas interesantes para la explicación de las complicidades y alianzas en el exilio. Obviamente, la red de relaciones es directamente proporcional a la duración del exilio fuera del país de origen, a su participación en la sociedad de acogida y el papel político que desempeña en el exilio de la

\footnotetext{
36 Sobre la elaboración del discurso mítico del héroe véase, entre otros, CENTLIVRES, P., FABRE, D. y ZONABEND, F.: La fabrique des héros. Paris, Mission du Patrimoine Ethnologique, Collection Ethologie de la France, Cahier 12, 1998.

37 Para una perspectiva sobre el problema véase FERRO, Marc: Os Tabus da História. A face oculta de acontecimentos que mudaram o mundo. São Paulo, Ediouro, 2003.

${ }^{38}$ Es el caso de Humberto Delgado, no es considerada su trayectoria como miembro del gobierno de Salazar. Véase ROSA, Frederico D.: op. cit.
} 
red. En este contexto, el descubrimiento de nuevos documentos en los archivos de los opositores exiliados puede ayudar a crear un balance de la historia del exilio y de la oposición, ya que puede presentar nuevos datos e incrementar el conocimiento sobre el papel desempeñado por sus miembros.

Finalmente, la recuperación de estos "agentes" de la historia contemporánea, algunos de ellos aún con vida, traslada el problema de la proximidad del historiador con su "objeto" de estudio y la distancia necesaria para un análisis del papel que desempeñaron en el movimiento de oposición. Lejos de reabrir el debate sobre la imparcialidad del historiador, el problema que se plantea es el poder de fascinación que puede producir los archivos y testimonios orales inéditos. Existe el peligro de que el historiador reproduzca el discurso emocional y las informaciones o recuerdos que retratan la óptica del informante o su partido. La fuente oral es una fuente que necesita ser verificada con otros documentos y relatos disponibles. El compromiso entre los testigos históricos y los investigadores debe incluir una perfecta comprensión por parte de los primeros de la necesidad de averiguar los datos recabados y buscar otras versiones acerca de los hechos ${ }^{39}$.

Esto no quiere decir que la investigación siempre coloque en tela de juicio el papel de los personajes históricos como símbolos de un movimiento de oposición, sino que su acción debe ser vista más allá del discurso mítico forjado en determinado momento político. La deconstrucción de las imágenes de los "héroes" puede contribuir a la comprensión de las fuerzas que actúan en determinado momento histórico, explicando las razones que llevaron al desarrollo de tales discursos por parte de la oposición. A través de las biografías de los exiliados, siempre que se respeten las reglas metodológicas normales de cualquier obra historiográfica, los historiadores pueden recuperar memorias perdidas, ocupar espacios vacíos dejados por la Historia Oficial y enriquecer el debate historiográfico en su país y fuera de sus fronteras.

\footnotetext{
39 Véase, entre otros, PAULO, H.: "Recordar é viver? Os problemas da memória e a memória como um problema para o historiador", en Estudos do Século XX. Coimbra, Imprensa da Universidade, 2011, pp. 121136.
} 